\title{
Comparisons of Late Ordovician ecosystem dynamics before and after the Richmondian invasion reveal consequences of invasive species in benthic marine paleocommunities
}

\author{
Hannah L. Kempf* (D), Ian O. Castro, Ashley A. Dineen, Carrie L. Tyler, and \\ Peter D. Roopnarine
}

\begin{abstract}
A thorough understanding of how communities respond to extreme changes, such as biotic invasions, is essential to manage ecosystems today. Here we constructed fossil food webs to identify changes in Late Ordovician (Katian) shallow-marine paleocommunity structure and functioning before and after the Richmondian invasion, a well-documented ancient invasion. Food webs were compared using descriptive metrics and cascading extinction on graphs models. Richness at intermediate trophic levels was underrepresented when using only data from the Paleobiology Database relative to museum collections, resulting in a spurious decrease in modeled paleocommunity stability. Therefore, museum collections and field sampling may provide more reliable sources of data for the reconstruction of trophic organization in comparison to online data repositories. The invasion resulted in several changes in ecosystem dynamics. Despite topological similarities between pre- and postinvasion food webs, species loss occurred corresponding to a minor decrease in functional groups. Invaders occupied all of the preinvasion functional guilds, with the exception of four incumbent guilds that were lost and one new guild, corroborating the notion that invaders replace incumbents and fill preexisting niche space. Overall, models exhibited strong resistance to secondary extinction, although the postinvasion community had a lower threshold of collapse and more variable response to perturbation. We interpret these changes in dynamics as a decrease in stability, despite similarities in overall structure. Changes in food web structure and functioning resulting from the invasion suggest that conservation efforts may need to focus on preserving functional diversity if more diverse ecosystems are not inherently more stable.
\end{abstract}

Hannah L. Kempf. Department of Earth and Planetary Sciences, University of California-Davis, Davis, California 95616, U.S.A. E-mail: hlkempf@ucdavis.edu

Ian O. Castro. Department of Geology, University of Cincinnati, Cincinnati, Ohio 45221, U.S.A. E-mail: castroio@ mail.uc.edu

Ashley A. Dineen. University of California Museum of Paleontology, University of California-Berkeley, Berkeley, California 94720, U.S.A. E-mail: aadineen@berkeley.edu

Carrie L. Tyler. Department of Geology and Environmental Earth Science, Miami University, Oxford, Ohio 45056, U.S.A. E-mail: tylercl@miamioh.edu

Peter D. Roopnarine. Department of Invertebrate Zoology and Geology, California Academy of Sciences, San Francisco, California 94118, U.S.A. E-mail: proopnarine@calacademy.org

Accepted: 7 June 2020

Data available from the Dryad Digital Repository: https://doi.org/10.25338/B8T31B

*Corresponding author.

\section{Introduction}

Biotic invasions are a leading cause of extinction in modern ecosystems (Eldredge 1992; Lodge 1993; Lockwood and Pimm 1994; Singh 2002; Lockwood et al. 2007; Oliver et al. 2015); however, their effects on ecosystem structure and functioning remain poorly understood. Data before invasion are rare, and studies are typically restricted to only a few species over short ecological timescales (Stouffer et al. 2012; David et al. 2017; Mollot et al. 2017). Yet ongoing anthropogenic effects, most notably global climate change, are likely to increase the taxonomic breadth and richness of species movements over the coming decades and centuries, particularly as habitats are altered. Geographic ranges change as species track shifting environments, and interspecific relationships are disrupted as a consequence. These changes have much in common with episodes of biotic interchanges and invasions in the geological past, commonly occurring during previous warming intervals, and are predicted to occur in the near future (Vermeij 
and Roopnarine 2008; Stigall 2019). Ancient invasions, although represented over longer temporal scales, were mechanistically and biologically comparable to modern invasions, and can be used to directly assess the ecological and evolutionary consequences of invasions (Stigall 2019). In addition, the fossil record documents persistent ecosystem dynamics (Aberhan 1994) and can be used to understand how and why ecosystems change in response to perturbations (Jackson et al. 2001; Miller et al. 2002; Jackson and Erwin 2006; Dzialowski et al. 2007; Sperfeld et al. 2010; Louys et al. 2012; Gray et al. 2015; Roopnarine 2018; Tyler and Schneider 2018; Stigall 2019). Therefore, here, we compare food webs across the Richmondian invasion, a well-documented invasion, to determine its effects on the structure and dynamics of Late Ordovician shallowmarine paleocommunities from the Cincinnati region (USA).

Biotic invasions preserved in the fossil record are well studied and are characterized by a hierarchical system based on the spatial scale of success and the relative evolutionary and ecological impacts (Stigall 2019). During the Late Ordovician (Katian), marine paleocommunities of the Cincinnati Basin were thought to be compositionally stable (i.e., little faunal turnover) for several million years until connected with previously isolated basins by rising sea levels (Patzkowsky and Holland 1997; Holland and Patzkowsky 2007; Malizia and Stigall 2011). This facilitated the rapid widespread influx of more than 60 genera to the region over a relatively short period of $\sim 1$ Myr termed the "Richmondian invasion" (Anstey 1986; Patzkowsky and Holland 1993, 1996, 1997, 2007; Holland and Patzkowsky 2007; Dudei and Stigall 2010; Malizia and Stigall 2011; Brame and Stigall 2014). The Richmondian invasion therefore falls into the hierarchical category of "coordinated" invasions (Stigall 2019), as numerous taxa simultaneously emigrated from previously isolated basins over a relatively short period of time, which is thought to have resulted in substantial community turnover, niche differentiation, and community restructuring (Holland and Patzkowsky 2007; Stigall 2010; Stigall and Fine 2019). The invasion itself has been the subject of numerous studies focused on documenting the invasion, as well as changes in diversity and community structure (e.g., Patzkowsky and Holland 1996; Holland 1997; Holland and Patzkowsky 2007), the geographic extent of the invasion (e.g., Stigall 2010), and shifts in geographic range and niche occupation (e.g., Dudei and Stigall 2010; Malizia and Stigall 2011; Tyler and Leighton 2011; Walls and Stigall 2012). This study builds on and extends this earlier work by directly assessing changes in trophic energy flow and paleocommunity structure using networks of trophic interactions (food webs).

The effects of invasions on food webs vary. As immigrating species can occur at any trophic level, and have both direct and indirect effects, invasions frequently result in changes of trophic structure and functional richness (Wonham and Pachepsky 2006; Byrnes et al. 2007; Gido and Franssen 2007; Olden et al. 2007; Romanuk et al. 2009; Comte et al. 2017; David et al. 2017). Competitive effects may arise, negatively affecting incumbents (Thomsen et al. 2014), and ecological displacement may occur, restricting the realized niche of incumbents to promote coexistence with invaders by reducing dietary overlap (Malizia and Stigall 2011; Tyler and Leighton 2011; Stigall 2014; David et al. 2017). Shifts in the number and/or intensity of species interactions can also alter the division of the network into modules, that is, groups of guilds more densely connected among themselves than to the rest of the network (Newman 2006; Pascual and Dunne 2006; Blondel et al. 2008; Rezende et al. 2009; Stouffer and Bascompte 2011). Such compartmentalization is widespread in modern food webs (Krause et al. 2003; Rezende et al. 2009; Guimerà 2010) and may increase food web stability and persistence by preventing propagation of perturbations between species (Krause et al. 2003; Newman 2006; Gross et al. 2009; Stouffer and Bascompte 2011)

To evaluate the effects of a coordinated invasion on paleocommunity structure and functioning, Late Ordovician shallow-marine food webs from before and after the Richmondian invasion were compared. First, the potential effects of various data sources on assessments of ecosystem structure and functioning were examined by constructing food webs produced 
using three datasets: museum collections and fieldwork, online data repositories, and both datasets combined. Using the dataset that performed most reliably, differences in pre- and postinvasion food web structure and dynamics were then assessed, by comparing food web topology and modeling paleocommunity stability. Differences between the pre- and postinvasion food webs would corroborate previous work, suggesting that this invasion ultimately led to community reorganization, and the potential for invasions to result in long-term reductions in stability. Understanding how the establishment of non-endemic species in the geologic past affected certain marine ecosystems can provide unique insights into the consequences of anticipated immigrations and invasions expected to occur in the coming decades, particularly in the Arctic and Antarctic (Arntz et al. 2005; Gili et al. 2006; Willis and Birks 2006; Vermeij and Roopnarine 2008; Aronson et al. 2015).

\section{Materials and Methods}

Geologic Setting.-During the Late Ordovician, the Cincinnati Basin of modern Ohio, Indiana, and Kentucky was located along a gently dipping carbonate ramp in a shallow ( 30 m) epeiric sea (Holland 1993), situated distal to the Taconic foreland basin, approximately $20^{\circ} \mathrm{S}$ (Scotese and McKerrow 1990). The region consists primarily of interbedded fossiliferous limestones and shale originally divided into third-order stratigraphic sequences, C1-C6 (Holland and Patzkowsky 1996), and more recently revised and split into eight sequences representing $7 \mathrm{Myr}$ (Brett et al. 2020). Here we use the revised nomenclature of Brett et al. (2020) when referring to sequences (C1-C8) (Fig. 1). Today, the region consists primarily of fossiliferous limestones and shale, and four depositional environments are widely recognized within each sequence: offshore, deep subtidal, shallow subtidal, and peritidal (Frey and Pemberton 1985; Brett and Baird 1986; Holland 1993; Holland and Patzkowsky 1996; Holland et al. 2001; Brett et al. 2015, 2020). Previous studies have argued that ecological stability (i.e., low turnover) existed throughout the $\mathrm{C} 1-\mathrm{C} 3$ sequences across onshore/offshore gradients, with a subsequent breakdown in the $\mathrm{C} 4$ sequence and gradient reestablishment in the C5-C7 sequences (Holland and Patzkowsky 2007). The invasion is preserved in the Sunset through the Clarksville Members of the Cincinnatian Series (C4 and C5B lithostratigraphic units of Brett et al. [2020]). The invasion was a pulsed event, with the most significant phase occurring abruptly in the $\mathrm{C} 5$, in the Clarksville-middle Rowland Member (C5B; Brett et al. 2020). Brief, unsuccessful repeated invasions occurred in the $\mathrm{C} 4$ sequence and resulted in the extinction of incumbent taxa (Brett et al. 2020). This trend of repeated invasion corresponds with patterns in modern invasions where species are introduced multiple times before they become established (Zenni and Nunez 2013; David et al. 2017). However, reinvasion here occurs over time frames on the order of tens of thousands of years, consistent with coordinated invasions (Stigall 2019). Nonnative species occupied a variety of trophic levels and included tabulate and rugosan corals, trilobites, gastropods, bivalves, brachiopods, and nautiloids (Foerste 1917; Holland and Patzkowsky 2007; Stigall 2010). Immigrating taxa were likely transported into the basin via multiple routes within Laurentia and Baltica due to climate-related changes in ocean circulation and sea level (Patzkowsky and Holland 1996; Holland 1997; Stigall 2010; Wright and Stigall 2013; Lam and Stigall 2015; Stigall and Fine 2019). The processes that initiated the Richmondian invasion were in many ways similar to current oceanographic changes related to modern climate change.

Food webs from pre- and postinvasion paleocommunities were reconstructed. Each food web included samples from shallow and deep subtidal facies from laterally adjacent paleoenvironments: the preinvasion Fairview (C2, deep subtidal) and Bellevue (C3, shallow subtidal) Formations, and the postinvasion Liberty (C6, deep subtidal) and Whitewater (C7, shallow subtidal) Formations (Holland 1993). The Fairview and Liberty Formations represent shallow transitional facies with approximately equal proportions of limestone and shale above fair-weather base, while the Bellevue and Whitewater Formations represent shallower, shoreface facies with greater proportions 


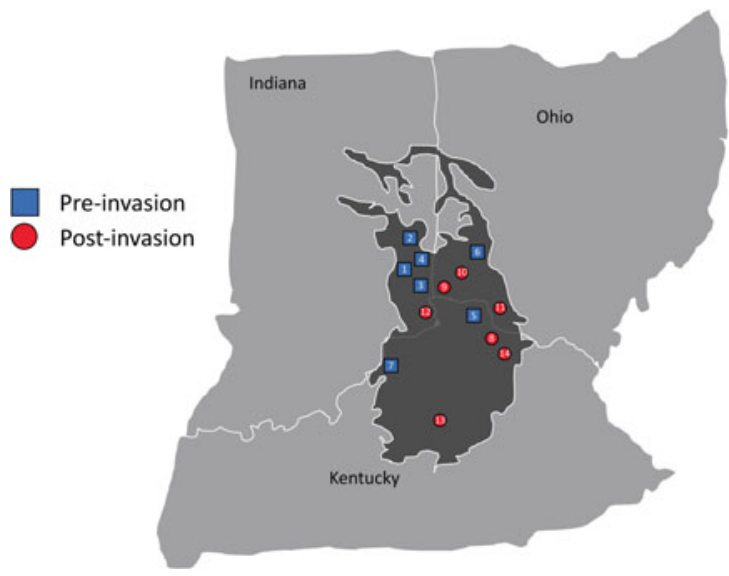

\begin{tabular}{|c|c|c|c|c|}
\hline sasen & 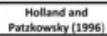 & Breet (2020) & Formetion & Member \\
\hline \multirow{3}{*}{$\frac{5}{8}$} & \multirow{2}{*}{ c6 } & c8 & $\sim$ Exhorm & \\
\hline & & C7 & wicenater & \\
\hline & & c6 & $\begin{array}{ll}\text { Libentry } \\
\end{array}$ & 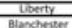 \\
\hline \multirow{3}{*}{$\frac{c}{\frac{c}{x}}$} & cs & cs & wapresule & Carisostle \\
\hline & $c_{4}$ & \multirow{2}{*}{ C4 } & \multirow[t]{2}{*}{ Anntem } & Oregonis \\
\hline & & & & Met Auburr \\
\hline \multirow{4}{*}{ 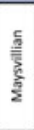 } & $\mathrm{c}_{3}$ & \multirow{2}{*}{ c3 } & \multirow[t]{2}{*}{ Grant lake } & Corrmalle \\
\hline & \multirow{3}{*}{$c_{2}$} & & & Berlevere \\
\hline & & \multirow{2}{*}{$c_{2}$} & \multirow{2}{*}{ Fanier } & Fasmoum \\
\hline & & & & Me Hope \\
\hline \multirow{3}{*}{ 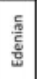 } & \multirow{3}{*}{$c_{1}$} & \multirow{3}{*}{ c1 } & \multirow{3}{*}{ Kope } & Mackicien \\
\hline & & & & Soutrene \\
\hline & & & & Economr \\
\hline
\end{tabular}

FIGURE 1. Field sample localities (left) and stratigraphic framework (right). Squares correspond to preinvasion localities, circles correspond to postinvasion localities, and numbers within symbols correspond with locality information in Table 1 . The dark gray area represents the extent of Ordovician rock exposed at the surface in the region. The simplified stratigraphic column is modified after Brett et al. (2020). See also Holland and Patzkowsky (1996).

of limestone (Tobin 1982, 1986; Holland 1993, 1997; Holland and Patzkowsky 1996). As these facies represent continuous shallow-marine habitats above storm wave base $(<30 \mathrm{~m})$, it was assumed that species within and across facies had the potential to interact, and sampling was intended to capture species occurrence data from laterally adjacent habitats on a spatial scale comparable to studies of modern shallowmarine food webs (e.g., Roopnarine and Hertog 2013). This study aims to assemble basinlevel food webs before and after the invasion in comparable depositional environments, which is achieved through the inclusion of multiple data types sampling the four formations listed. Although this approach ensures that samples from a range of localities across stratigraphic dip were employed (see "Food Web Construction"), combining data from two formations preinvasion (Fairview and Bellevue) and two postinvasion (Liberty and Whitewater) increased temporal mixing. However, the stratigraphic third-order sequences represent unconformity bounded packages of 0.5-2 Myr in duration (Brett et al. 2020). Thus, combining samples from different formations nevertheless resulted in food webs that represented average trophic structure across $<2$ Myr, a relatively short temporal scale over which to examine generalities in trophic structure in the fossil record. Further, these represent the same suite of depositional environments, so disparities between communities are unlikely to arise as a result of abiotic change.

Food Web Construction. - The potential effects of data sources on trophic structure have not yet been evaluated when reconstructing fossil food webs, and the inclusion or omission of key species could bias reconstructions of trophic relationships. Therefore, changes in food web structure and functioning across the invasion were first compared using six food webs constructed using the following types of data: (1) species lists downloaded from the Paleobiology Database (PBDB; www.paleobiodb.org), (2) species lists compiled from museum collections and field-collected material (referred to as "specimen-based data"), and (3) a combined species list assembled using both the PBDB and specimen-based sources. Pre- and postinvasion food webs were constructed using each of the three data types, and food web structure and functioning were compared across the invasion to determine how each data type performed. If all three data sources yield comparable food webs and consistent paleocommunity structure and functioning across the invasion, then the choice of data source may not significantly affect trophic structure in paleo-food web reconstructions. However, food webs representing the same paleocommunity, but constructed using different data sources, may exhibit disparities in structure and/or dynamics. Species occurrence 
data from online repositories such as the PBDB, which archive data from scientific publications, may differ in temporal or spatial scope and resolution relative to datasets compiled by individual researchers (Alroy 2003).

To construct pre- and postinvasion food webs for each data set, six species lists were assembled. Species lists were downloaded from the PBDB for each formation (downloaded July 2016) and combined to form one pre- and one postinvasion dataset. Similarly, pre- and postinvasion species lists were obtained from nine museum collections and field sampling. Museum data were obtained from the University of Cincinnati's Invertebrate Paleontology collection and the Miami University Karl E. Limper Museum Invertebrate Paleontology collection. Additional museum collection data were downloaded via the iDigBio specimen portal (downloaded March 2017) from the Harvard Museum of Natural History, the Oklahoma Museum of Natural History, Kansas University Biodiversity Institute and Natural History Museum, the Smithsonian National Museum of Natural History, the Florida Museum of Natural History, University of Central Missouri, and the North Carolina Museum of Natural Sciences. Museum data were augmented with field sampling to increase the proportion of species with controlled metadata (e.g., geographic location and formation) and unbiased collecting. Field samples consisted of both bulk and targeted surficial sampling. Bulk sampling resulted in the collection of $\sim 38 \mathrm{~L}$ from each of 14 field localities throughout the Cincinnati region, seven preinvasion and seven postinvasion (Fig. 1). At six of these localities, two formations were present, and thus both were sampled, resulting in a total of 20 samples pre- and postinvasion, respectively, totaling $\sim 757 \mathrm{~L}$ of sediment (Table 1). Samples were wet-sieved (1-mm mesh) and air dried, and macrofossils were identified to the lowest taxonomic level (typically species) using various sources (Feldman and Hackathorn 1996; Davis and Meyer 2009), yielding a total of 5867 identified specimens. Bryozoans from field sampling were not included, as species identifications require thin sections.

To assemble the six food webs, for each species list, species were aggregated into trophic guilds (Dryad doi: https://doi.org/10.25338/ B8T31B). Interactions between these guilds were inferred using extensive literature surveys of species life mode, feeding habits, functional morphology (e.g., feeding apparatus), habitat, species associations, and living analogue species (Steineck and Casey 1990; Frey 1995; Fortey and Owens 1999; Williams et al. 2000; Rezende et al. 2009; Arapov 2010; Bush and Bambach 2011; Stigall 2015). Trophic interactions have been similarly inferred in paleocommunities elsewhere (Dunne et al. 2008, 2014; Roopnarine et al. 2007; Mitchell et al. 2012; Roopnarine 2018; Roopnarine and Dineen 2018). As the methodology for species aggregation into trophic guilds is consistent across pre- and postinvasion food webs, as are the types of organisms, any dissimilarities between the food webs should result from differences in species occurrences and structural differences between food webs. These trophic guild food webs are in some ways comparable to cumulative food webs, which are widely used to examine food web structure (Stouffer et al. 2005; Dunne et al. 2008).

Food Web Structure.-The structure of preand postinvasion food webs was compared between data types and across the invasion to assess differences between data sources and identify changes in paleocommunity structure due to the invasion. If immigrating species occupied the same trophic guilds as incumbents, either outcompeting incumbents, or coexisting in unsaturated niche space, little change in the number and distribution of trophic guilds and guild interactions should occur. If new species succeeded in unoccupied niche space (adding guilds) or led to the local extinction of incumbents (reducing guilds), functional richness and the number of trophic guild interactions may either increase or decrease respectively. Note that changes in the number of species would not necessarily correspond to changes in the number of trophic guilds and/or interactions, that is, species richness can increase without resulting in an increase in functional richness. Changes in guild richness may also alter the trophic distribution of guilds (their energetic position in a food web) via the addition or loss of guilds at various trophic positions. Generalities in food 
TABLE 1. GPS coordinates for all field localities. Coordinates are in degrees. RI, Richmondian invasion. Numbers correspond to localities in Fig. 1.

\begin{tabular}{llccc}
\hline \hline Type & Locality & Number & GPS coordinates & Formations \\
\hline Post-RI & Bon Well Hill Roadcut & 1 & $39.438,-84.988$ & Liberty \\
Post-RI & Brookeville Dam Causeway & 2 & $39.508,-85.008$ & Liberty \\
Post-RI & Southgate Hill & 3 & $39.339,-84.953$ & Liberty \\
& & 3 & & Whitewater \\
Post-RI & Garr Hill, IN-101 & 4 & $39.489,-84.949$ & Liberty \\
& & 4 & & Whitewater \\
Post-RI & AA Highway, 5.8 km north of KY-345 & 5 & $38.700,-83.954$ & Liberty \\
Post-RI & Caesar Creek Spillway and Dam & 6 & $39.485,-84.063$ & Liberty \\
& & 6 & & Whitewater \\
Post-RI & Madison 421 \& 62 & 7 & $39.485,-84.064$ & Liberty \\
Pre-RI & Taylor Mill, KY-11 & 8 & $38.613,-83.756$ & Fairview \\
& & 8 & $39.157,-84.566$ & Bellevue \\
Pre-RI & Montana Avenue, I-74 Ramp & 9 & $39.296,-84.404$ & Fairview \\
Pre-RI & Trammel Fossil Park & 10 & 10 & Fairview \\
Pre-RI & Georgetown & 11 & $38.872,-83.917$ & Bellevue \\
Pre-RI & Lawrenceburg IN-48 & 12 & $39.096,-84.876$ & Fairview \\
& & 12 & 13 & Fairview \\
Pre-RI & Clays Ferry & 14 & $37.881,-84.340$ & Bellevue \\
Pre-RI & AA Highway at KY-1449 & & $38.585,-83.701$ & Fairview \\
\hline
\end{tabular}

web structure were therefore calculated using graph theory to quantitatively compare preand postinvasion food web structures. Descriptive metrics including the number of trophic guilds, network trophic position (ntp), and number of trophic links (consumer-resource interactions between guilds) were calculated to quantify species' hierarchical position within food webs. Trophic position describes the number of intermediaries between basal organisms and predators in a food web (Pimm and Lawton 1978). Here we quantify the position of guilds in the food web, using network trophic position (ntp), the average shortest distance to a primary producer guild calculated as:

$$
\mathrm{ntp}_{i}=2+\frac{1}{r_{i}} \sum_{j=1}^{S} a_{i j}\left(l_{j}\right)
$$

where trophic position is calculated for trophic guild $i ; r_{i}$ is the number of consumer guilds; $S$ is the number of trophic guilds in the food web; variable $a_{i j}$ is either 0 or 1 , where 1 indicates that guild $i$ preys upon guild $j$; and $l_{j}$ is the length of the shortest path of guild $j$ to a primary producer guild (Roopnarine and Dineen 2018). Descriptive metrics were calculated using custom code written by C.L.T. in $\mathrm{R}$ v. 3.3.1 employing the igraph package (Csárdi and Nepusz 2006; Kones et al. 2009; Hudson et al. 2013; R Development Core Team 2013), and ntp was calculated using custom code written by P.D.R. in Julia (Bezanson et al. 2017). The ntp distributions were compared using a Kruskal-Wallis test in R.

Groups of guilds with more mutual interactions than expected form compartments, or modules (Gross et al. 2009; Stouffer and Bascompte 2011). The propagation of secondary extinction across modules may be reduced if a community is more compartmentalized, thereby increasing stability (Krause et al. 2003; Newman 2006; Gross et al. 2009; Stouffer and Bascompte 2011). The number and size of compartments may be altered by changes in trophic organization, as well as the strength of compartmentalization (referred to as modularity). Larger proportions of generalist species may lead to a fusion of modules and a more cohesive network (Olesen et al. 2007; Padrón et al. 2009; Albrecht et al. 2014). If many invaders were generalists (Marvier et al. 2004; Stigall 2010, 2012; Malizia and Stigall 2011), the postinvasion food web would have had fewer modules and therefore would be less stable. After the invasion, we would also expect an increase in modularity if the number and strength of species interactions increased, that is, greater competition between species utilizing similar resources (Pascual and Dunne 2006). Calculating and interpreting modularity is feasible, because fossil food webs have been found to 
reliably record guild richness and evenness, trophic-level distribution, predator dietary breadth, food chain lengths, and modularity despite the preferential loss of soft-bodied taxa to poor preservation (i.e., reductions in species richness, and the number of interactions) (Roopnarine and Dineen 2018). Hierarchical clustering community detection methods were used to identify natural divisions within the food web into compartments (Newman 2006). The number of modules and modularity were calculated using the Louvain algorithm, which finds community structure by multilevel optimization of modularity (Blondel et al. 2008).

As higher trophic positions are often represented by rare species, if either the PBDB or specimen-based data sources produce a larger species pool, the likelihood of including more species at higher trophic positions would be greater (Alroy 2003). The size of the species pool derived from the PBDB could be affected in various ways. A greater number of species in the PBDB may be subject to outdated taxonomic identifications or "lumping" of taxa, reducing richness (Prothero 2015). For example, in some taxonomic groups identification to the species level may be particularly challenging, leading to the use of higher levels of taxonomic classification. Bryozoans, for example, require thin sections and extensive experience to identify to the species level. Alternatively, in cases where samples entered into the PBDB were collected, identified, and verified by taxonomic experts, these data may be accurate (Alroy 2003). However, outdated taxonomic classifications, incorrect geographic data, and missing key species, attributed to outdated identification or classifications employed during data entry, a lack of filters for taxonomic wastebasket terms, and transcription errors, are also likely to be present in the PBDB (Prothero 2015). The pervasiveness of these errors may be difficult to assess across taxonomic groups (Prothero 2015). In museum collections, taxonomic classifications that are well maintained and frequently updated may be more reliable, for example, at institutions with strong research backgrounds for the taxa, region, or geologic intervals represented (Ponder et al. 2001). However, collections can be biased toward higher- quality specimens intended for display or taxonomic description and identification, potentially omitting poorly preserved taxa or taxa already highly abundant in the collection, depressing species richness for a locality or region (Alroy 2002). Paleocommunities assembled through fieldwork and/or museum collections can also be biased by the taxonomic expertise of the collectors, concentrating collection efforts to portions of the paleocommunity or increasing the accuracy of species identification for some groups. Therefore, differences between food webs may arise due to the resulting differences in the trophic distribution of richness.

Species-Level Food Web Modeling.-We hypothesized that preinvasion food webs would be more stable and resistant to collapse, as the community represented a purportedly stable system before disturbance and potential community reorganization (Holland and Patzkowsky 2007). However, if the invasion altered food web structure, changes in stability may have resulted. Studies of the structural organization of detritus-based ecosystems, such as those of the Late Ordovician, are rare, and our understanding of the dynamics of detritusbased ecosystems and their responses to perturbation remains limited (but see Tavares-Cromar and Williams 1996; Hildrew 2009; Calizza et al. 2015). Empirical studies have shown that detritus is a consistent and readily available resource compared with phytoplankton (Moore et al. 2004), and more realized trophic pathways to top predators exist in benthic food webs that derive energy from detrital basal resources (i.e., they show greater architectural complexity) (Raffaelli et al. 2003). Detritus-based food chains are thus thought to be important in stabilizing food webs, performing key functional roles (Moore et al. 2004; Costantini and Rossi 2010; Rooney and McCann 2012). Therefore, when detritus chains are affected by perturbations, the potential for indirect effects and trophic cascades is likely to be high. Here we assess stability and paleocommunity dynamics using the cascading extinction on graphs (CEG) model, designed specifically to take into account uncertainty in paleontological community data (see Roopnarine 2006, 2010, 2018). A paleocommunity's trophic structure, although 
accurate, can never be precisely specified by a single topology (Roopnarine 2006, 2010, 2018; Roopnarine and Dineen 2018), because no food web reconstruction (modern or fossil) can capture all species interactions. Therefore, CEG stochastically generates species-level food webs by randomly and repeatedly drawing species from the trophic guilds and assigning them as predators and prey within the constraints of the trophic guild food web assembled as described earlier. Each species-level food web is a hypothesized representation of the paleocommunity, and each species is constrained to the potential interactions for its guild, as specified by the guild-level food web. For each species-level food web, CEG then employs a form of deletion stability modeling by removing increasing increments of primary producers, initiating trophic cascades of secondary extinctions that propagate through the food web. Primary productivity was modeled as a function of the density of herbivorous interactions (Angielczyk et al. 2005; Roopnarine 2006; Roopnarine et al. 2007), scaling productivity as 10 times that of herbivore richness in accordance with general assimilation efficiency between tropic levels. Although there was a period of rapid planktonic diversification throughout the Ordovician (Servais et al. 2016), autotrophic phytoplankton were grouped into one guild based on predator-prey relationships that remain similar across genera, as the data available were not sufficient to distinguish them.

One hundred species-level food webs were stochastically generated for each of the six paleocommunities, three preinvasion and three postinvasion, yielding average community responses to simulated perturbations for each food web. Model responses to simulated perturbations were then compared to evaluate differences in stability and resistance to the propagation of secondary extinction between paleocommunities. If the specimen-based data included fewer species from higher trophic levels relative to the PBDB, specimen-based models may have relatively lower stability and resistance. Alternatively, specimen-based data may yield higher richness relative to the $\mathrm{PBDB}$, if the number of species in the PBDB is reduced by outdated taxonomic identifications and "lumping" of taxa (Prothero 2015). If this is the case, specimen-based models may have greater stability and resistance relative to the PBDB data models. Differences between preand postinvasion stability and resistance would also suggest trophic restructuring occurred, altering paleocommunity stability. Collapse thresholds are marked by a dramatic increase in secondary extinction and were compared between communities to examine resistance to the propagation of secondary extinction, with higher perturbation thresholds associated with more robust communities. Collapse thresholds were calculated using the $R$ package changepoint, in which statistical changes in the data sequence were detected implementing the pruned exact linear time, or PELT, algorithm (Killick and Eckley 2014). The changepoint value was identified for each of the 100 species-level food webs, and differences in the mean perturbation magnitude at which the pre- and postinvasion collapse thresholds occurred were evaluated using a $t$-test. In addition, variability in trophic cascades - the range of secondary extinction observed for each perturbation thresholdwas used to assess relative stability. Highly variable responses to perturbations suggest sensitive community arrangements that facilitate a wide range of responses to perturbations. Differences in variability between models were assessed using the coefficient of variation, which was calculated for each simulation. The coefficients were then statistically compared using a Kruskal-Wallis test. Here we define "resistance" as the fraction of a community that persists after perturbation and subsequent secondary extinctions in CEG, that is, more-resistant communities have lower proportions of secondary extinction overall in response to repeated perturbation. Higher stability would therefore lead to a relatively narrower range of secondary extinction values for each perturbation magnitude.

\section{Results}

Food Web Structure.-The PBDB data included 159 species $(n=2471)$ preinvasion versus 268 species $(n=3221)$ in the specimenbased data (Table 2). The PBDB data included 
133 species $(n=3050)$ postinvasion relative to 197 species $(n=4858)$ in the specimen-based data. All species from field collections were present in museum collections, and $45 \%$ of species in museum collections were also present in field collections preinvasion, and $72 \%$ postinvasion. Similarly, the PBDB and specimenbased data shared high percentages of species, with $63 \%$ of the preinvasion species and $85 \%$ of the postinvasion species present in both datasets.

Changes in food web structure across the invasion varied depending on the data source (Table 3). In the PBDB food web, the number of guilds decreased from 23 to 21, while in the specimen-based food web, the number of trophic guilds increased after the invasion from 20 to 21. However, both food webs contained identical guilds postinvasion (Fig. 2). The number of links (i.e., interactions) decreased in the PBDB food web from 63 to 56 and increased in the specimen-based food web from 54 to 56 . There were three modules in food webs for both data subsets, thus compartmentalization was consistent, and modularity increased postinvasion for both (Table 3). Maximum ntp increased marginally across the invasion in food webs for both data sources, from 3.6 to 3.7, and mean ntp decreased from 2.0 to 1.8. The ntp values were not significantly different between the specimen-based and PBDB food webs in either the pre- or postinvasion intervals $\left(\chi^{2}=0.001, p=0.96\right.$, and $\chi^{2}=0, p=1$, respectively). The PBDB subset included fewer total species, but richness was lower predominantly in intermediate trophic levels relative to the specimen-based dataset, at or near ntp 2.5 both pre- and postinvasion (Fig. 3).

In food webs assembled using the combined dataset, including all data sources, species richness decreased after the invasion from 358 preinvasion to 241, with only 67 shared species (Table 2). Similarly, the number of trophic guilds (pre 24; post 21), trophic links (pre 64; post 55), and modules (4 pre; 3 post) all decreased (Table 3, Fig. 2). In contrast, modularity increased moderately from 0.31 to 0.32 after the invasion. Maximum ntp values for pre- and postinvasion communities ranged from 3.6 to 3.8 , average ntp decreased moderately from 2.13 to 1.90 and differed significantly $\left(\chi^{2}=18, p=0.02\right)$. Richness was predominantly concentrated in suspension-feeding guilds at intermediate trophic levels (ntp 2.5). Four guilds present in the preinvasion paleocommunities were absent postinvasion (Fig. 2), each of which contained only a single species: Detritivore II (polychaete), Grazer I (polychaete), Suspension Feeder II (polychaete), and Suspension Feeder VII (filter-feeding trilobite); however, one new guild appeared postinvasion, Predator VII (eurypterid). Three of these guilds were linked directly to detritus, thus their loss led to the postinvasion being reduced from eight to five detrital chains (Fig. 2).

Species-Level Food Web Modeling.-CEG models employing the specimen-based data were consistent with models using the combined datasets, producing comparable results across the invasion. Simulations in both sets of models responded uniformly to perturbations with low variability in secondary extinction at all perturbation levels and comparable collapse thresholds (Fig. 4). However, models utilizing the PBDB subset differed substantially. Although the preinvasion model response was relatively consistent with the specimenbased data, the postinvasion PBDB models exhibited highly variable reactions to perturbation (Fig. 5), with high variation that differed significantly $\left(\chi^{2}=548.53, p<0.001\right)$ among individual simulations, reaching up to $60 \% \mathrm{sec}-$ ondary extinction before reaching a less pronounced collapse threshold. The mean collapse threshold identified by the changepoint analysis differed significantly pre- and postinvasion in the specimen-based data $(t=$ $-26, p<0.001)$; however, changepoint was unable to identify a collapse threshold in the postinvasion PBDB data due to the sigmoidal shape of the curve.

The threshold of collapse (i.e., a dramatic increase in secondary extinction) for our fulldataset CEG analysis was reached at a mean perturbation magnitude of 0.68 and 0.66 in the pre- and postinvasion paleocommunities, respectively (Fig. 4), and this difference was significant $(t=33.4, p<<0.001)$. Overall, CEG models exhibited a uniform response to perturbation among species-level food webs (Fig. 4). However, the postinvasion community appeared to be less stable and exhibited greater 
TABLE 2. Sample sizes from various data sources. $N$ represents abundance; $\%$ Shared species refers to the percentage shared between the specimen-based (SB) and Paleobiology Database (PBDB) subsets. For example, in the preinvasion data $100 \%$ of the species from field samples and $45 \%$ of the species in museum collections were present in the PBDB data subset, while $63 \%$ of the species in the PBDB subset were also present in the combined museum and field subset. The richness of the specimen-based and PBDB subsets do not sum to the combined richness, due to shared species.

\begin{tabular}{|c|c|c|c|c|c|c|c|}
\hline \multirow[b]{2}{*}{ Sources } & \multirow[b]{2}{*}{ Data type } & \multicolumn{3}{|c|}{ Preinvasion } & \multicolumn{3}{|c|}{ Postinvasion } \\
\hline & & $N$ & Richness & $\%$ Shared species & $N$ & Richness & $\%$ Shared species \\
\hline All & Combined & 5744 & 358 & - & 8158 & 241 & - \\
\hline Field & SB & 2851 & 27 & 100 & 3016 & 32 & 100 \\
\hline Museum & SB & 422 & 268 & 45 & 2092 & 197 & 72 \\
\hline PBDB & PBDB & 2471 & 159 & 63 & 3050 & 133 & 85 \\
\hline
\end{tabular}

TABLE 3. Food web structure. Metrics describing food web structure before and after the invasion for all data and data subsets. Significant changes in species richness, guild richness, and the number of modules were observed pre- and postinvasion. However, consistent network trophic position (ntp) distribution, and modularity suggest that overall ecosystem structure did not change drastically after the invasion. Different data sources produced somewhat different quantitative metrics of food web structure, and relative changes across the invasion were inconsistent. For example, for food webs constructed using all data combined or the Paleobiology Database (PBDB), the number of guilds decreases postinvasion, while using only the specimen-based data increases the number of guilds by one. RI, Richmondian invasion.

\begin{tabular}{|c|c|c|c|c|c|c|}
\hline & \multicolumn{2}{|c|}{ All data } & \multicolumn{2}{|c|}{ Specimen based } & \multicolumn{2}{|c|}{ PBDB } \\
\hline & Pre-RI & Post-RI & Pre-RI & Post-RI & Pre-RI & Post-RI \\
\hline Species richness & 364 & 241 & 274 & 195 & 157 & 131 \\
\hline Guild richness & 24 & 21 & 20 & 21 & 23 & 21 \\
\hline Trophic links & 64 & 55 & 54 & 56 & 63 & 56 \\
\hline Max. ntp & 3.6 & 3.8 & 3.63 & 3.77 & 3.63 & 3.77 \\
\hline Mean ntp & 2.13 & 1.90 & 1.85 & 1.90 & 2.05 & 1.89 \\
\hline No. of modules & 4 & 3 & 3 & 3 & 3 & 3 \\
\hline Modularity & 0.31 & 0.32 & 0.29 & 0.32 & 0.25 & 0.32 \\
\hline
\end{tabular}

variability in species-level food web responses (Fig. 5) with significantly higher mean coefficients of variation $\left(\chi^{2}=203.83, p<<0.001\right)$ relative to the preinvasion community.

\section{Discussion}

Comparisons of Data Sources: Specimen-based versus PBDB.-Specimen-based data yielded higher richness relative to the $\mathrm{PBDB}$, which could be due to differences in collection methods or data quantity or quality. However, differences in species occurrence lists resulted in only minor changes in guild food web structure. Although the absolute values differed between data sources, the relative change across the invasion was consistent. For example, the strength of the division into compartments (i.e., modularity) increased, and the average ntp increased slightly in all three postinvasion food webs. Given the consistency between metrics quantifying food web structure, such as the number of modules, modularity, and trophic levels, either data type could be appropriate for studies utilizing these analyses to assess paleocommunity structure. As museum collections become increasingly digitized, both collections and digital data repositories may be widely available to researchers interested in the application of food webs to understanding changes in ecosystem functioning. The addition of systematically collected field samples also did not contribute novel species (all 59 species from field samples were present in both museum collections and the PBDB), and substantial efforts over multiple field seasons would be necessary to document rare taxa, typical of higher trophic levels. Museum collections with a strong regional focus including a breadth of taxa and rare specimens thus serve as a valuable resource for trophic reconstructions.

In contrast to the comparisons of trophic structure, the specimen-based and PBDB data subsets produced different modeled paleocommunity dynamics. The specimen-based dataset 


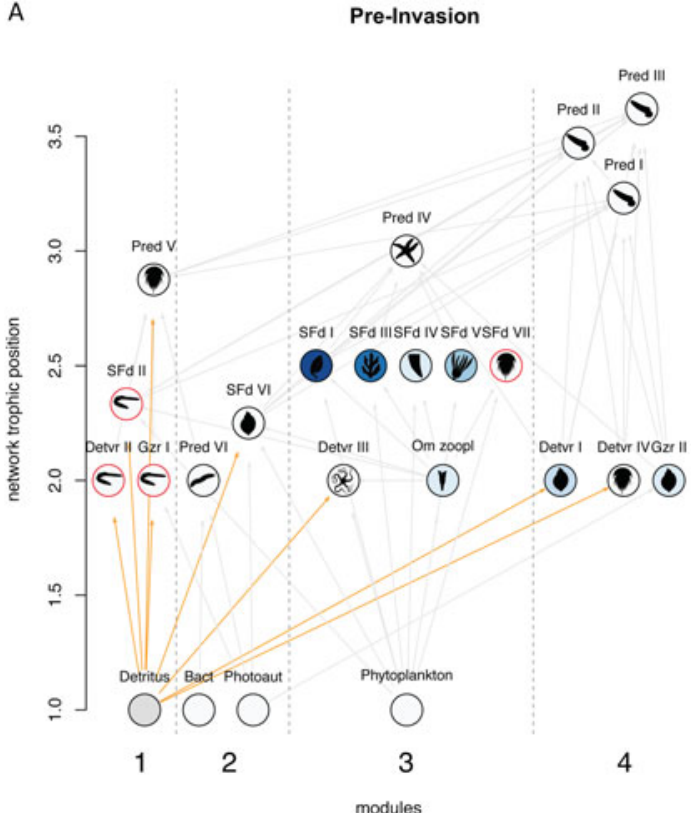

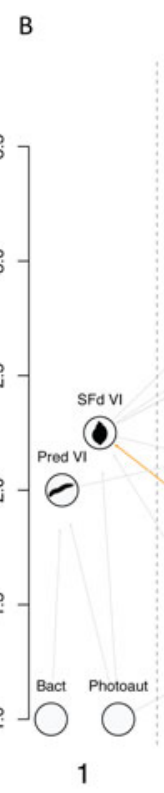

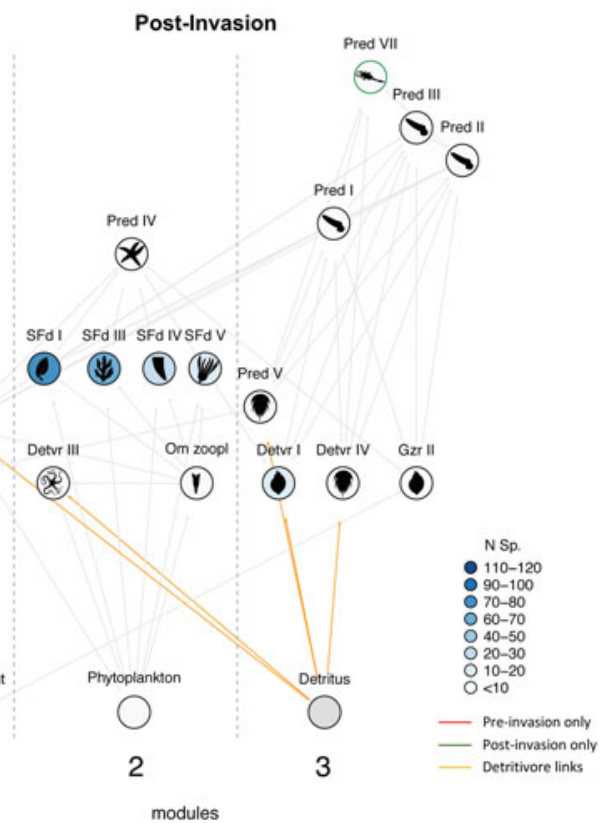

FIGURE 2. Food webs. Trophic guild food webs for the preinvasion paleocommunity (A) and postinvasion paleocommunity (B). Circles are trophic guilds, connected by gray lines representing consumer-resource interactions. Images in circles represent the most diverse clade within that guild and are not the only type of organisms in any given guild. Trophic guilds are arranged by module (compartment) along the $\mathrm{x}$-axis, and increasing network trophic position (ntp) along the y-axis, and color intensity indicates increasing species richness within guilds. Guild names are abbreviated as follows: Pred = predator; $\mathrm{SFd}$ = suspension feeder; Om zoopl = omnivorous micro-zooplankton; Detvr = detritivore; Gzr = grazer; Photoaut $=$ photoautotroph. Roman numerals following guild names indicate similar types of functional guilds with distinct interactions (i.e., although functionally similar, guilds could not be aggregated due to different consumer-resource relationships). Guilds outlined in red are present preinvasion, but absent postinvasion, and the guild outlined in green is unique to the postinvasion food web. Links between trophic guilds are orange if they are linked directly to detritus, and there is a decrease in the number of guilds linked to detritus in the postinvasion food web. N Sp, number of species.

produced model responses that were overall more similar to the full dataset, while the PBDB subset yielded highly unstable dynamics in the postinvasion CEG models, suggesting spurious model volatility introduced by missing influential guilds and/or species. Although the larger community structure was relatively consistent for both data subsets, the stochastic generation of species-level food webs produced highly divergent CEG model outcomes, that is, paleocommunity dynamics. Overall, the PBDB data yielded less stable paleocommunities, indicated by highly variable ranges in the proportions of secondary extinction and by a postinvasion switch from an exponential to logistic collapse curve. The higher richness of the specimen-based subset relative to the PBDB subset was important for modeling community dynamics, particularly with regard to reduced richness of guilds at intermediate trophic levels. In addition, subsetting the data led to the omission of several guilds. Their absence may also have made the food web more susceptible to trophic cascades in the CEG models. These differences suggest that datasets including substantial contributions from fieldwork and/or museum collections may be relatively better suited to analyses of trophic organization and paleocommunity dynamics. Further, data from online repositories, such as the PBDB, should be supplemented with additional data sources to ensure the highest available representation of species at all trophic levels. Additional studies of differences in trophic distributions across data types from other time periods and locations are necessary to assess the pervasiveness of potential data type disparities.

Differences in the results of the comparative species-level food web modeling between 


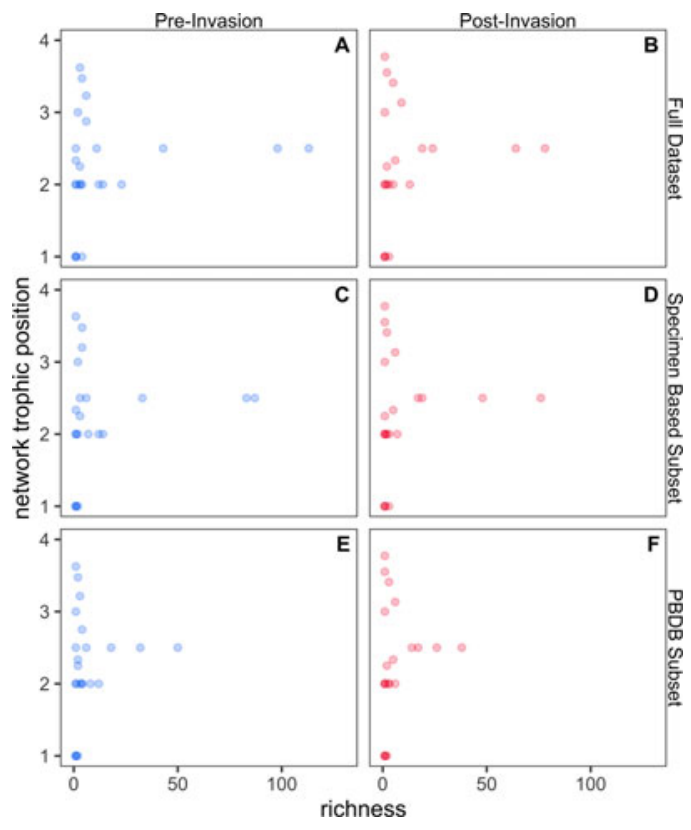

FIGURE 3. Trophic distribution of richness. The number of species per guild relative to the guild network trophic position (ntp) for the combined preinvasion (A) and postinvasion (B), specimen-based preinvasion (C) and specimenbased postinvasion (D), and Paleobiology Database (PBDB) preinvasion (E) and PBDB postinvasion (F) datasets. In all food webs, richness was highest at intermediate ntp values. Richness in the PBDB data subset was lower overall, and the reduction in species was concentrated at ntp 2.5 .

datasets suggest that influential species and/or guilds were missing from the PBDB dataset, producing highly volatile model responses. In addition, the combined data provided results consistent with the specimen-based analysis and included the largest taxonomic list, and thus captured a more comprehensive biotic suite (i.e., the maximum representation of functional diversity and trophic positions). Therefore, we limit our discussion of the potential effects of invasion on paleocommunity structure and dynamics to the results derived from the combined dataset.

Food Web Structure.-The combined dataset suggests substantial species turnover (replacement of 291 species) and an overall decrease in richness postinvasion of 117 species that resulted in a reduction of functional richness and the loss of four guilds (Table 3, Fig. 2). However, average ntp and modularity did not differ significantly after the invasion, suggesting remarkably consistent trophic organization across the invasion despite these losses. The arrival of new taxa did not equate to an increase in the number or types of interactions between trophic guilds. This departs from studies that have suggested that the invasion increased biodiversity (Patzkowsky and Holland 1996, 2007; Holland and Patzkowsky 2007) and resulted in community reorganization (Holland and Patzkowsky 2007; Stigall 2010). Here, we document a decrease in richness in the Richmondian stage postinvasion paleocommunity, with profound species turnover corresponding to functional homogenization (loss of guilds). Interestingly, the postinvasion non-endemic species occupied almost all of the preexisting functional guilds from the preinvasion community. One guild is unique to the postinvasion food web, which consists of the eurypterid genus Megalograptus. This is consistent with previous reports of Megalograptus only occurring in the upper Cincinnatian (e.g., Alexander 1986; Frey 1989; Tetlie 2007). Although the Cincinnatian strata have been extensively sampled (e.g., Patzkowsky and Holland 1996, 2007; Holland et al. 2001; Holland and Patzkowsky 2007; Holland 2008), and our dataset represents, to our knowledge, the largest compilation of museum collections and published reports of pre- and postinvasion paleocommunities, it is nevertheless possible that the apparent arrival of Megalograptus is an artifact of the rarity of eurypterid fossils in the region during the Late Ordovician or a preservation bias relating to differences in lithologies and does not represent a new postinvasion functional group.

Previous studies on the invasion have argued that generalists occupying larger geographic areas preferentially survived the invasion (Marvier et al. 2004; Malizia and Stigall 2011; Stigall 2012). Empirical results in plantpollination food webs have shown that greater proportions of generalists can lead to a more cohesive network (Olesen et al. 2007; Albrecht et al. 2014), and thus loss of modules. Therefore, based on previous observations, we predicted that if many new taxa were generalists, the postinvasion food web would have fewer modules and therefore would be less stable (Stouffer and Bascompte 2011). The minor decrease in stability in the postinvasion CEG models and the reduction of modules may 

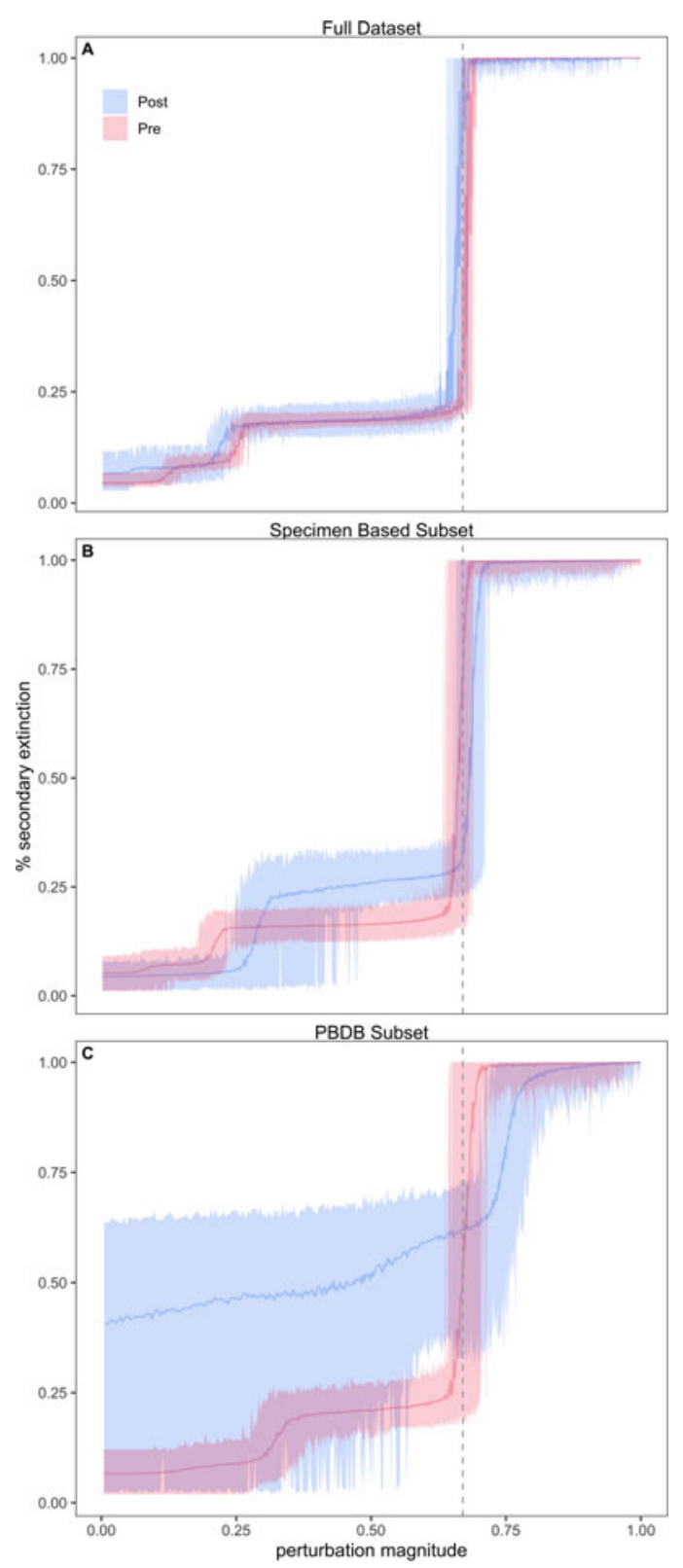

FIGURE 4. Cascading extinction on graphs (CEG) models. $A$, The full dataset; $B$, the specimen-based data subset; and $C$, the Paleobiology Database (PBDB) data subset. Shaded regions encompass the range of individual permutations of the perturbation of 100 stochastically generated species-level food webs, with dark lines denoting the mean. Dashed lines indicate the preinvasion collapse threshold in each graph. In the full dataset (A), the postinvasion community threshold of collapse typically occurred at lower perturbation magnitudes relative to the preinvasion, and total collapse occurred less frequently. Overall, both communities appear relatively stable, with wellconstrained ranges of secondary extinction. However, the postinvasion has a wider range of secondary extinctions, suggesting lower stability. When data were restricted to

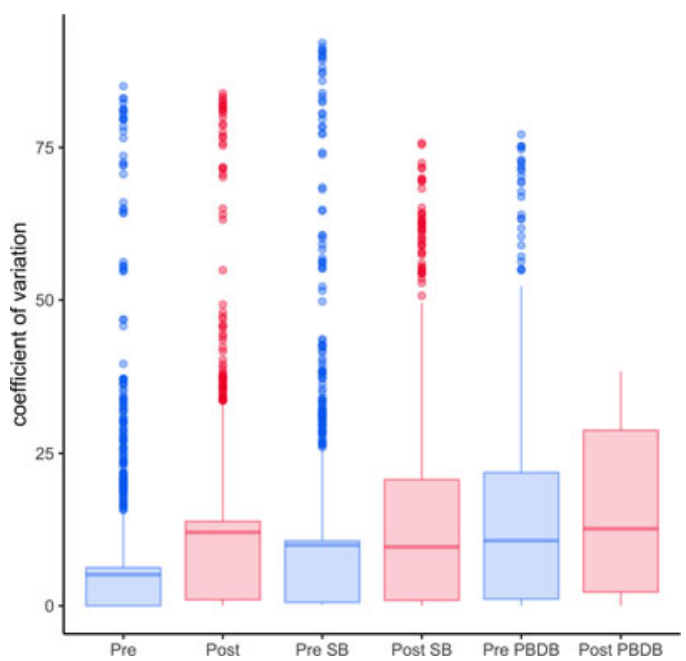

FIGURE 5. Variation in simulated secondary extinction. The median of the coefficient of variation for each simulation is higher postinvasion for the combined dataset (pre- and postinvasion), and differs significantly $\left(\chi^{2}=203.83, p<<\right.$ $0.001)$. The range is greater in the postinvasion models for all three datasets, and is largest in the Paleobiology Database (PBDB) data subsets.

therefore be due to an increase in generalism postinvasion. Additional studies directly assessing changes in the proportion of generalist taxa across the invasion are, however, necessary to test this hypothesis.

Species-Level Food Web Modeling.-Despite the loss of species and functional groups, only minor differences were observed in the paleocommunity dynamics modeled here. A small, but significant amount of destabilization occurred, and greater sensitivity to perturbation was observed postinvasion. This was likely caused by the loss of species richness, one module, three detritivore guilds, or some combination thereof. Although compartmentalization is thought to stabilize food webs (Stouffer and Bascompte 2011), and the loss of one module postinvasion could have led to

the specimen-based subset (B), variation in model responses increased, and the collapse threshold occurred at lower perturbation magnitudes in the preinvasion (a reversal from the full dataset). The PBDB subset models (C) yielded relatively consistent responses and mean collapse threshold in the preinvasion, but dramatically increased variability in secondary extinction cascades and a less pronounced collapse threshold signal were observed postinvasion. 
destabilization, that relationship was not clearly observed. Given the overall consistency in dynamics across the invasion, our specieslevel food web models suggest that conservation and ecosystem management may need to focus on preventing functional homogenization, as stability was not greatly reduced despite the loss of 117 species. If functional richness plays a critical role in ecosystem resistance on evolutionary timescales, additional investigation of the Richmondian invasion could provide unique insight into the consequences of anticipated asymmetric invasions expected to occur in the coming century. Paleozoic benthic marine ecosystems were in many ways functionally analogous to modern Arctic and Antarctic benthic marine ecosystems; they were dominated by suspension feeders and lacked durophagous predators (Aronson et al. 2001, 2007; Arntz et al. 2005; Gili et al. 2006). Arctic and Antarctic communities are expected to undergo widespread invasions and community change in the near future with rising ocean temperatures, particularly by bathyal crustaceans (Frenot et al. 2005; Aronson et al. 2007, 2015; Doney et al. 2012; Smith et al. 2017) and elasmobranchs (MacNeil et al. 2012; Campana et al. 2013). Although anticipated invasions may alter food webs, overall ecosystem stability may not change dramatically if functional richness is preserved.

\section{Conclusions}

The results of the specimen-based data analyses most closely tracked our full dataset. However, modeling of ecosystem dynamics resulted in variable outcomes depending on the data type used, highlighting problems associated with utilizing only subsets of all available data for paleo-food web reconstructions and suggesting that museum collections may be more suitable for fossil food web reconstructions than online data repositories. Additional empirical studies are necessary to reveal specific mechanisms that promote resistance at different scales of data collection. Pre- and postinvasion food webs consisted of remarkably consistent trophic organization despite high species turnover, and the Richmondian invasion resulted in only minor changes in paleocommunity structure, including functional homogenization and a decrease in the number of subcommunities (modules). However, these structural differences were sufficient to result in a small, but statistically significant, loss of stability. Therefore, modern ecosystems could be at risk of substantial destabilization in cases where dramatic functional homogenization occurs, pointing toward the preservation of functional diversity over species diversity in conservation and ecosystem management.

\section{Acknowledgments}

We thank the Paleontological Society, the Cincinnati Dry Dredgers, and Miami University for financial support. Further, we thank B. Hunda from the University of Cincinnati and K. Hauer from Miami University for access to museum collections, C. Brett for meaningful discussions regarding Cincinnatian stratigraphy and crinoid identifications, A. Stigall for a thoughtful review and discussions on Late Ordovician paleoecology, B. Datillo for a thoughtful and constructive review of the article, and the Ordovician Atlas of Life (ordovicianatlas.org). This research was funded by a National Science Foundation CAREER grant to C.L.T. (EAR-1848232).

\section{Literature Cited}

Aberhan, M. 1994. Guild-structure and evolution of Mesozoic benthic shelf communities. Palaios 9:516-545.

Albrecht, M., B. Padrón, I. Bartomeus, and A. Traveset. 2014. Consequences of plant invasions on compartmentalization and species' roles in plant-pollinator networks. Proceedings of the Royal Society of London B 281:20140773.

Alexander, R. R. 1986. Resistance to repair of shell breakage induced by durophages in Late Ordovician brachiopods. Journal of Paleontology 60:273-285.

Alroy, J. 2002. How many named species are valid? Proceedings of the National Academy of Sciences USA 99:3706-3711.

Alroy, J. 2003. Global databases will yield reliable measures of global biodiversity. Paleobiology 29:26-29.

Angielczyk, K. D., P. D. Roopnarine, and S. C. Wang. 2005. Modeling the role of primary productivity disruption in end-Permian extinctions, Karoo Basin, South Africa. Bulletin of the New Mexico Museum of Natural History 30:16-23.

Anstey, R.L. 1986. Bryozoan provinces and patterns of generic evolution and extinction in the Late Ordovician of North America. Lethaia 19:33-51.

Arapov, J. 2010. Bivalve feeding — how and what they eat? Croatian Journal of Fisheries 68:105-116. 
Arntz, W., S. Thatje, D. Gerdes, J. Gili, and J. Gutt. 2005. The Antarctic-Magellan connection: macrobenthos ecology on the shelf and upper slope, a progress report. Sciencia Marina 69:237-269.

Aronson, R., D. Blake, and T. Oji. 2001. Global climate change and the origin of modern benthic communities in Antarctica. American Zoologist 41:27-39.

Aronson, R. B., S. Thatje, A. Clarke, L. S. Peck, D. B. Blake, C. D. Wilga, and B. A. Seibel. 2007. Climate change and invasibility of the Antarctic benthos. Annual Review of Ecology, Evolution, and Systematics 38:129-154.

Aronson, R. B., K. Smith, S. Vos, J. McClintock, M. O. Amsler, P. O. Moksnes, D. S. Ellis, J. Kaeli, H. Singh, J. W. Bailey, J. C. Schiferl, R. van Woesik, M. A. Martina, B. V. Steffel, M. E. Deal, S. M. Lazarus, J. N. Havenhan, R. Swalethorp, S. Kjellerup, and S. Thatje. 2015. No barrier to emergence of bathyal king crabs on the Antarctic shelf. Proceedings of the National Academy of Sciences USA 112:12997-13002.

Bezanson, J., A. Edelman, S. Karpinski, and V. B. Shah. 2017. A fresh approach to numerical computing. SIAM Review 59:65-98.

Blondel, V., J. Guillaume, R. Lambiotte, and E. Lefebvre. 2008. Fast unfolding of communities in large network. Journal of Statistical Mechanics: Theory and Experiment 1:10008.

Brame, H., and A. L. Stigall. 2014. Controls on niche stability in geologic time: congruent responses to biotic and abiotic environmental changes among Cincinnatian (Late Ordovician) marine invertebrates. Paleobiology 40:70-90.

Brett, C. E., and G. C. Baird. 1986. Comparative taphonomy: a key to paleoenvironmental interpretation based on fossil preservation. Palaios 1:207-227.

Brett, C. E., T. J. Malgieri, J. R. Thomka, C. D. Aucoin, B. F. Dattilo, and C. E. Schwalbach. 2015. Calibrating water depths of Ordovician communities: lithological and ecological controls on depositional gradients in Upper Ordovician strata of southern Ohio and northcentral Kentucky, USA. Estonian Journal of Earth Sciences 64:19-23.

Brett, C.E., C. D. Aucoin, B. F. Dattilo, R. Freeman, K. R. Hartshorn, P. I. McLaughlin, and C. E. Schwalbach. 2020. Revised sequence stratigraphy of the upper Katian Stage (Cincinnatian) strata in the Cincinnati Arch reference area: geological and paleontological implications. Palaeogeography, Palaeoclimatology, Palaeoecology 540. doi: 10.1016/j.palaeo.2019.109483.

Bush, A. M., and R. K. Bambach. 2011. Paleoecologic megatrends in marine metazoa. Annual Review of Earth and Planetary Sciences 39:241-269.

Byrnes, J. E., P. L. Reynolds, J. J. Stachowicz, J. van Beusekom, and M. Busch. 2007. Invasions and extinctions reshape coastal marine food webs. PLoS ONE 2:e295.

Calizza, E., M. L. Costantini, and L. Rossi. 2015. Effect of multiple disturbances on food web vulnerability to biodiversity loss in detritus-based systems. Ecosphere 6:124.

Campana, S. E., A. T. Fisk, and P. Klimley. 2013. Movements of Arctic and northwest Atlantic Greenland sharks (Somniosus microcephalus) monitored with archival satellite pop-up tags suggest long-range migrations. Deep-Sea Research, part II (Topical Studies in Oceanography) 115:109-115.

Comte, L., J. Cucherousset, and J. Olden. 2017. Global test of Eltonian niche conservatism of nonnative freshwater fish species between their native and introduced ranges. Ecography 39:1-9.

Costantini, M., and L. Rossi. 2010. Species diversity and decomposition in laboratory aquatic systems: the role of species interactions. Freshwater Biology 55:2281-2295.

Csárdi, G., and T. Nepusz. 2006. The igraph software package for complex network research. InterJournal Complex Systems 1695.

David, P., E. Thébault, O. Anneville, P. F. Duyck, E. Chapuis, and N. Loeuille. 2017. Impacts of invasive species on food webs. Advances in Ecological Research 56:1-60.
Davis, R. A., and D. L. Meyer. 2009. A sea without fish: life in the Ordovician Sea of the Cincinnati Region. Indiana University Press, Bloomington.

Doney, S., M. Ruckelshaus, J. Duffy, J. Barry, F. Chan, C. English, H. Galindo, J. Grebmeier, A. Hollowed, N. Knowlton, J. Polovina, N. Rabalais, W. Sydeman, and L. Talley. 2012. Climate change impacts on marine ecosystems. Annual Review of Marine Science 4:11-37.

Dudei, N. L., and A. L. Stigall. 2010. Using ecological niche modeling to assess biogeographic and niche response of brachiopod species to the Richmondian Invasion (Late Ordovician) in the Cincinnati Arch. Palaeogeography, Palaeoclimatology, Palaeoecology 296:28-43.

Dunne, J., R. Williams, N. Martinez, R. Wood, and D. Erwin. 2008. Compilation and network analyses of Cambrian food webs. PLoS Biology 6:693-708.

Dunne, J. A., C. C. Labandeira, and R. J. Williams. 2014. Highly resolved early Eocene food webs show development of modern trophic structure after the end-Cretaceous extinction. Proceedings of the Royal Society of London B 281:20133280.

Dzialowski, A. R., J. T. Lennon, and V. H. Smith. 2007. Food web structure provides biotic resistance against plankton invasion attempts. Biological Invasions 9:257-267.

Eldredge, N. 1992. Systematics, ecology, and the biodiversity crisis. Columbia University Press, New York.

Feldman, R. M., and E. Hackathorn. 1996. Fossils of Ohio. State of Ohio Department of Natural Resources, Columbus.

Foerste, A. F. 1917. Notes on Richmond and related fossils. Journal of the Cincinnati Society of Natural History 22:42-55.

Fortey, R. A., and R. M. Owens. 1999. Feeding habits in trilobites. Palaeontology 42:429-465.

Frenot, Y., S. Chown, J. Whinam, P. Selkirk, P. Convey, M. Skotnicki, and D. Bergstrom. 2005. Biological invasions in the Antarctic: extent, impacts and implications. Biological Reviews 80:45-72.

Frey, R. C. 1989. Paleoecology of a well-preserved nautiloid assemblage from a Late Ordovician shale unit, southwestern Ohio. Journal of Paleontology 63:604-620.

Frey, R. C. 1995. Middle and Upper Ordovician nautiloid cephalopods of the Cincinnati Arch region of Kentucky, Indiana, and Ohio. Contributions to the Ordovician paleontology of Kentucky and nearby states. U.S. Geological Survey Professional Paper 1066:1-126.

Frey, R. W., and S. G. Pemberton. 1985. Biogenic structures in outcrops and cores: approaches to ichnology. Bulletin of Canadian Petroleum Geology 33:72-115.

Gido, K. B., and N. R. Franssen. 2007. Invasion of stream fishes into low trophic positions. Ecology of Freshwater Fish 16:457-464.

Gili, J. M., W. E. Arntz, A. Palanques, C. Orejas, A. Clarke, P.K. Dayton, E. Isla, N. Teixidó, S. Rossi, and P. J. LópezGonzález. 2006. A unique assemblage of epibenthic sessile suspension feeders with archaic features in the high-Antarctic. Deep-Sea Research, part II (Topical Studies in Oceanography) 53:1029-1052.

Gray, S. M., D. E. Dykhuizen, and D. K. Padilla. 2015. The effects of species properties and community context on establishment success. Oikos 124:355-363.

Gross, T., L. Rudolf, S. A. Levin, and U. Dieckmann. 2009. Generalized models reveal stabilizing factors in food webs. Science 325:747-750

Guimerà, R. 2010. Origin of compartmentalization in food webs. Ecology 91:2941-2951.

Hildrew, A. G. 2009. Sustained research on stream communities: a model system and the comparative approach. Advances in Ecological Research 41:175-312.

Holland, S. M. 1993. Sequence stratigraphy of a carbonate-clastic ramp: the Cincinnatian Series (Upper Ordovician) in its type area. Geological Society of America Bulletin 105:306-322. 
Holland, S. M. 1997. Using time/environment analysis to recognize faunal events in the Upper Ordovician of the Cincinnati Arch. Pp. 309-334 in C. E. Brett and G. C. Baird, eds. Paleontological events: stratigraphic, ecological, and evolutionary implications. Columbia University Press, New York.

Holland, S. M. 2008. The type Cincinnatian: an overview. Pp. 174-184 in G. W. McLaughlin, C. E. Brett, S. M. Holland, and P. I. Storrs, eds. Stratigraphic renaissance in the Cincinnati Arch: implications for Upper Ordovician paleontology and paleoecology. Cincinnati Museum Center Scientific Contributions, Cincinnati, Ohio.

Holland, S. M., and M. E. Patzkowsky. 1996. Sequence stratigraphy and long-term paleoceanographic change in the Middle and Upper Ordovician of the eastern United States. Pp. 117-129 in B. J. Witzke, G. A. Ludvigsen, and J. Day, eds., Paleozoic sequence stratigraphy: views from the North American craton. Geological Society of America Special Paper, Boulder, Colo.

Holland, S. M., and M. E. Patzkowsky. 2007. Gradient ecology of a biotic invasion: biofacies of the type Cincinnatian Series (Upper Ordovician), Cincinnati, Ohio Region, USA. Palaios 22:392-407.

Holland, S. M., A. I. Miller, D. L. Meyer, and B. F. Dattilo. 2001. The detection and importance of subtle biofacies within a single lithofacies: the Upper Ordovician Kope Formation of the Cincinnati, Ohio region. Palaios 16:205-217.

Hudson, L. N., R. Emerson, G. B. Jenkins, K. Layer, M. E. Ledger, D. E. Pichler, M. S. A. Thompson, E. J. O'Gorman, G. Woodward, and D. C. Reuman. 2013. Cheddar: analysis and visualization of ecological communities in R. Methods in Ecology and Evolution 4:99-104.

Jackson, J. B. C., and D. H. Erwin. 2006. What can we learn about ecology and evolution from the fossil record? Trends in Ecology and Evolution 21:322-328.

Jackson, J. B. C., M. X. Kirby, W. H. Berger, K. A. Bjorndal, L. W. Botsford, B. J. Bourque, R. H. Bradbury, R. Cooke, J. Erlandson, J. A. Estes, T. P. Hughes, S. Kidwell, C. B. Lange, H. S. Lenihan, M. Pandolfi, C. H. Peterson, R. S. Steneck, M. J. Tegner, R. R. Warner, and J. M. Pandolfi. 2001. Historical overfishing and the recent collapse of coastal ecosystems. Science 293:629-638.

Killick, R., and I. A. Eckley. 2014. Changepoint: an R package for changepoint analysis. Journal of Statistical Software 58: 1-19.

Kones, J. K., K. Soetaert, D. van Oevelen, and J. Owino. 2009. Are network indices robust indicators of food web functioning? A Monte Carlo approach. Ecological Modeling 220:370-882.

Krause, A., K. Frank, D. Mason, R. Ulanowicz, and W. Taylor. 2003. Compartments revealed in food-web structure. Nature 426:282-285.

Lam, A.R., and A. L. Stigall. 2015. Pathways and mechanisms of Late Ordovician (Katian) faunal migrations of Laurentia and Baltica. Estonian Journal of Earth Sciences 64:62-67.

Lockwood, J. L., and S. L. Pimm. 1994. Biological diversity. Species: would any of them be missed? Current Biology 4:455-457.

Lockwood, J. L., M. F. Hoopes, and M. P. Marchetti. 2007. Invasion ecology. Wiley-Blackwell, Oxford, U.K., 1-392.

Lodge, D. M. 1993. Biological invasions: lessons for ecology. Trends in Ecology and Evolution 8:133-137.

Louys, J., D. M. Wilkinson, and L. C. Bishop. 2012. Ecology needs a paleontological perspective. Pp. 23-38 in J. Louys, ed. Paleontology in Ecology and Conservation. Springer, New York.

MacNeil, M. A., B. C. McMeans, N. E. Hussey, P. Vecsei, J. Svavarsson, K. M. Kovacs, C. Lydersen, M. A. Treble, G. B. Skomal, M. Ramsey, and A. T. Fisk. 2012. Biology of the Greenland shark Somniosus microcephalus. Journal of Fish Biology 80:991-1018.

Malizia, R. W., and A. L. Stigall. 2011. Niche stability in Late Ordovician articulated brachiopod species before, during, and after the Richmondian Invasion. Palaeogeography, Palaeoclimatology, Palaeoecology 311:154-170.
Marvier, M., P. Kareiva, and M. G. Neubert. 2004. Habitat destruction, fragmentation, and disturbance promote invasion by habitat generalists in a multispecies metapopulation. Risk Analysis 24:869-878

Miller, T. E., J. M. Kneitel, and J. H. Burns. 2002. Effect of community structure on invasion success and rate. Ecology 83:898-905.

Mitchell, J. S., P. D. Roopnarine, and K. D. Angielczyk. 2012. Late Cretaceous restructuring of terrestrial communities facilitated the end-Cretaceous mass extinction in North America. Proceedings of the National Academy of Sciences USA 109:18857-18861. Mollot, G., J. H. Pantel, and T. N. Romanuk. 2017. The effects of invasive species on the decline in species richness: a global meta-analysis. Advances in Ecological Research 56:61-83.

Moore, J., E. L. Berlow, D. C. Coleman, P. C. De Suiter, Q Dong, A. Hastings, N. C. Johnson, K. S. McCann, K. Melville, P. J. Morin, K. Nadelhoffer, A. D. Rosemond, D. M. Post, J. L. Sabo, K. M. Scow, M. J. Vanni, and D. H. Wall. 2004. Detritus, trophic dynamics and biodiversity. Ecology Letters 7:584-600.

Newman, M. E. J. 2006. Modularity and community structure in networks. Proceedings of the National Academy of Sciences USA 103:8577-8582.

Olden, J. D., B. J. Pusey, and M. J. Kennard. 2007. Species invasions and the changing biogeography of Australian freshwater fishes. Global Ecology and Biogeography 17:25-37.

Olesen, J., J. Bascompte, Y. L. Dupont, and P. Jordano. 2007. The modularity of pollination networks. Proceedings of the National Academy of Sciences USA 104:19891-19896.

Oliver, T. H., M. S. Heard, N. J. B. Isaac, D. B. Roy, D. Procter, F. Eigenbrod, R. Freckleton, A. Hector, C. D. L. Orme, O. L. Petchey, V. Proença, D. Raffaelli, K. B. Suttle, G. M. Mace, B. Martín-López, B. A. Woodcock, and J. M. Bullock. 2015. Biodiversity and resilience of ecosystem functions. Trends in Ecology and Evolution 30:673-684

Padrón, B., A. Traveset, T. Briedenweg, D. Díaz, M. Nogales, and J. M. Olesen. 2009. Impact of alien plant invaders on pollination networks in two archipelagos. PLoS One 4:e6275.

Pascual, M., and J. A. Dunne. 2006. Ecological networks: linking structure to dynamics in food webs. Oxford University Press, New York.

Patzkowsky, M. E., and S. M. Holland. 1993. Biotic response to a middle Ordovician paleoceanographic event in eastern NorthAmerica. Geology 21:619-622.

Patzkowsky, M. E., and S. M. Holland. 1996. Extinction, invasion, and sequence stratigraphy: patterns of faunal change in the Middle and Upper Ordovician of the eastern United States. Geological Society of America Special Paper 306:131-142.

Patzkowsky, M. E., and S. M. Holland. 1997. Patterns of turnover in Middle and Upper Ordovician brachiopods of the eastern United States: a test of coordinated stasis. Paleobiology 23:420-443.

Patzkowsky, M. E., and S. M. Holland. 2007. Diversity partitioning of a Late Ordovician marine biotic invasion: controls on diversity in regional ecosystems. Paleobiology 33:295-309.

Pimm, S.L., and J. H. Lawton. 1978. On feeding on more than one trophic level. Nature 275: 542-544.

Ponder, W. F., G. A. Carter, P. Flemons, and R. R. Chapman. 2001. Evaluation of museum collection data for use in biodiversity assessment. Conservation Biology 15:648-657.

Prothero, D. 2015. Garbage in, garbage out: the effects of immature taxonomy on database compilations of North American fossil mammals. New Mexico Museum of Natural History and Science Bulletin 68:257-264.

Raffaelli, D., E. M. Bell, G. Weithoff, A. K. Matsumoto, J. J. Cruz-Motta, P. J. Kershaw, E. R. Parker, D. Parry, and M. Jones. 2003. The ups and downs of benthic ecology: considerations of scale, heterogeneity and surveillance for benthic- 
pelagic coupling. Journal of Experimental Marine Biology and Ecology 285:191-203.

R Development Core Team. 2013. R: a language and environment for statistical computing. R Foundation for Statistical Computing, Vienna, Austria.

Rezende, E., E. Albert, M. Fortuna, and J. Bascompte. 2009. Compartments in a marine food web associated with phylogeny, body mass, and habitat structure. Ecology Letters 12:779-788.

Romanuk, T. N., Y. Zhou, U. Brose, E. L. Berlow, R. J. Williams, and N. D. Martinez. 2009. Predicting invasion success in complex ecological networks. Philosophical Transactions of the Royal Society of London B 364:1743-1754.

Rooney, N., and K. McCann. 2012. Integrating food web diversity, structure and stability. Trends in Ecology and Evolution 27:40-46.

Roopnarine, P. D. 2006. Extinction cascades and catastrophe in ancient food webs. Paleobiology 32:1-19.

Roopnarine, P. D. 2010. Networks, extinction, and paleocommunity food webs. Paleontological Society Papers 16:143-161

Roopnarine, P. D. 2018. Ecological modeling of paleocommunity food webs. Pp. 201-305 in G. Dietl and K. Flessa, eds. Conservation paleobiology. Science and practice. University of Chicago Press, Chicago.

Roopnarine, P. D., and A. A. Dineen. 2018. Coral reefs in crisis: the reliability of deep-time food web reconstructions as analogs for the present. Pp. 105-141 in C. L. Tyler and C. L. Schneider, eds. Marine conservation paleobiology. Springer International, New York.

Roopnarine, P. D., and R. Hertog. 2013. Detailed food web networks of three Greater Antillean coral reef systems: the Cayman Islands, Cuba and Jamaica. Dataset Papers in Ecology 23:9.

Roopnarine, P. D., K. D. Angielczyk, S. C. Wang, and R. Hertog. 2007. Trophic network models explain instability of Early Triassic terrestrial communities. Proceedings of the Royal Society of London B 274:2077-2086.

Scotese, C. R., and W. S. McKerrow. 1990. Revised world maps and introduction. In W. S. McKerrow and C. R. Scotese, eds. Paleozoic paleogeography and biogeography. Geological Society of London Memoir 12:1-21.

Servais, T., V. Perrier, T. Danelian, C. Klug, R. Martin, A. Munnecke, H. Nowak, A. Nützelg, T. R. A. Vandenbroucke, M. Williams, and C. M. Ø. Rasmussen. 2016. The onset of the "Ordovician Plankton Revolution" in the late Cambrian. Palaeogeography, Palaeoclimatology, Palaeoecology 458:12-28.

Singh, J. S. 2002. The biodiversity crisis: a multifaceted review. Current Science 82:638-647.

Smith, K. E., R. B. Aronson, B. V. Steffel, M. O. Amsler, S. Thatje, H. Singh, J. Anderson, C. J. Brothers, A. Brown, D. S. Ellis, J. N. Havenhand, W. R. James, P. O. Moksnes, A. W. Randolph, T. Sayre-McCord, and J. B. McClintock. 2017. Climate change and the threat of novel marine predators in Antarctica. Ecosphere 8:e0217.

Sperfeld, E., A. Schmidtke, U. Gaedke, and G. Weithoff. 2010. Productivity, herbivory, and species traits rather than diversity influence invasibility of experimental phytoplankton communities. Oecologia 163:997-1010.

Steineck, P. L., and R. E. Casey. 1990. Ecology and paleobiology of foraminifera and radiolaria. Pp. 89-138 in G. M. Capriulo, ed. Ecology of marine protozoa. Oxford University Press, Oxford.

Stigall, A. L. 2010. Using GIS to assess the biogeographic impact of species invasions on native brachiopods during the Richmondian invasion in the Type-Cincinnatian (Late Ordovician, Cincinnati Region). Palaeontologica Electronica 13:19.

Stigall, A. L. 2012. Speciation collapse and invasive species dynamics during the Late Devonian "Mass Extinction." GSA Today 22:4-9.

Stigall, A. L. 2014. When and how do species achieve niche stability over long time scales? Ecography 37:1123-1132.
Stigall, A. L. 2015. Atlas of Ordovician life. www.ordovicianatlas. org, accessed September 2017.

Stigall, A. L. 2019. The invasion hierarchy: ecological and evolutionary consequences of invasions in the fossil record. Annual Review of Ecology, Evolution, and Systematics 50:355-380.

Stigall, A.L., and R. Fine. 2019. Contrasting ecosystem impacts of biotic invasions in the Type Cincinnatian Series (Late Ordovician, Katian). Palaeoworld 28:166-172.

Stouffer, D. B., and J. Bascompte. 2011. Compartmentalization increases food-web persistence. Proceedings of the National Academy of Sciences USA 108:3648-3652.

Stouffer, D. B., J. Camacho, R. Guimerà, C. A. Ng, and L. Amaral. 2005. Quantitative patterns in the structure of model and empirical food webs. Ecology 86:1301-1311.

Stouffer, D. B., M. Sales-Pardo, M. I. Sirer, and J. Bascompte. 2012. Evolutionary conservation of species' roles in food webs. Science 335:1489-1492.

Tavares-Cromar, A. F., and D. D. Williams. 1996. The importance of temporal resolution in food web analysis: evidence from a detritus-based stream. Ecological Monographs 66:91-113.

Tetlie, O. E. 2007. Distribution and dispersal history of Eurypterida (Chelicerata) Palaeogeography, Palaeoclimatology, Palaeoecology 52:557-574.

Thomsen, M. S., J. Byers, D. R. Schiel, J. F. Bruno, J. D. Olden, T. Wernberg, and B. R. Silliman. 2014. Impacts of marine invaders on biodiversity depend on trophic position and functional similarity. Marine Ecology Progress Series 495:39-47.

Tobin, R. C. 1982. A model for cyclic deposition in the Cincinnatian series of southwestern Ohio, northeastern Kentucky, and southeastern Indiana. Ph.D. dissertation, Department of Geology, University of Cincinnati, Cincinnati, Ohio.

Tobin, R. C. 1986. An assessment of the lithostratigraphic and interpretive value of the traditional "biostratigraphy" of the type Upper Ordovician of North America. American Journal of Science 286:673-701.

Tyler, C. L., and L. R. Leighton. 2011. Detecting competition in the fossil record: support for character displacement among Ordovician brachiopods. Palaeogeography, Palaeoclimatology, Palaeoecology 307:205-217.

Tyler, C.L., and C. L. Schneider. 2018. Conservation paleobiology: the need for a paleontological perspective. Pp. 1-10 in C. L. Tyler and C. L. Schneider, eds. Marine conservation paleobiology. Springer International, New York.

Vermeij, G. J., and P. D. Roopnarine. 2008. The coming Arctic invasion. Science 321:780-781.

Walls, B. J., and A. L. Stigall. 2012. A field-based analysis of the accuracy of niche models applied to the fossil record. Paleontological Contributions 6:1-13.

Williams, A., S. J. Carlson, and C. H. Brunton. 2000. Brachiopod classification. Pp. 1-21 in A. Williams, ed. Treatise on invertebrate paleontology, Vol. 2. Geological Society of America, Boulder, Colo.

Willis, K. J., and H. J. B. Birks. 2006. What is natural? The need for a long-term perspective in biodiversity conservation. Science 314:1261-1265.

Wonham, M. J., and E. Pachepsky. 2006. A null model of temporal trends in biological invasion records. Ecology Letters 9:663-672.

Wright, D.F., A. L. Stigall. 2013. Geologic drivers of Late Ordovician faunal change in Laurentia: investigating links between tectonics, speciation, and biotic invasions. PLoS One 8: e68353.

Zenni, R. D., and M. Nunez. 2013. The elephant in the room: the role of failed invasions in understanding invasion biology. Oikos 122:801-815. 